\title{
Carbon dioxide insufflation in open-chamber cardiac surgery: A double-blind, randomized clinical trial of neurocognitive effects
}

\author{
Krish Chaudhuri, MBBS, ${ }^{\text {a,b }}$ Elsdon Storey, D Phil, ${ }^{\mathrm{d}}$ Geraldine A. Lee, MPhil, ${ }^{\mathrm{a}}$ Michael Bailey, PhD, \\ Justin Chan, MBBS, ${ }^{\mathrm{a}}$ Franklin L. Rosenfeldt, MD, ${ }^{\text {a,b }}$ Adrian Pick, FRACS, ${ }^{\mathrm{a}}$ Justin Negri, FRACS, ${ }^{\mathrm{a}}$ \\ Julian Gooi, FRACS, ${ }^{\mathrm{a}}$ Adam Zimmet, FRACS, ${ }^{\mathrm{a}}$ Donald Esmore, MD, ${ }^{\mathrm{a}}$ Chris Merry, FRACS, ${ }^{\mathrm{a}}$ \\ Michael Rowland, FRACS, ${ }^{\mathrm{a}}$ Enjarn Lin, FANZCA, ${ }^{\mathrm{f}}$ and Silvana F. Marasco, MSc, MBBS, FRACS ${ }^{\mathrm{a}, \mathrm{b}, \mathrm{c}}$
}

\begin{abstract}
Objective: The aims of this study were first to analyze neurocognitive outcomes of patients after open-chamber cardiac surgery to determine whether carbon dioxide pericardial insufflation reduces incidence of neurocognitive decline (primary end point) as measured 6 weeks postoperatively and second to assess the utility of carbon dioxide insufflation in cardiac chamber deairing as assessed by transesophageal echocardiography.
\end{abstract}

\begin{abstract}
Methods: A multicenter, prospective, double-blind, randomized, controlled trial compared neurocognitive outcomes in patients undergoing open-chamber (left-sided) cardiac surgery who were assigned carbon dioxide insufflation or placebo (control group) in addition to standardized mechanical deairing maneuvers.
\end{abstract}

\begin{abstract}
Results: One hundred twenty-five patients underwent surgery and were randomly allocated. Neurocognitive testing showed no clinically significant differences in $z$ scores between preoperative and postoperative testing. Linear regression was used to identify factors associated with neurocognitive decline. Factors most strongly associated with neurocognitive decline were hypercholesterolemia, aortic atheroma grade, and coronary artery disease. There was significantly more intracardiac gas noted on intraoperative transesophageal echocardiography in all cardiac chambers (left atrium, left ventricle, and aorta) at all measured times (after crossclamp removal, during weaning from cardiopulmonary bypass, and at declaration of adequate deairing by the anesthetist) in the control group than in the carbon dioxide group $(P<.04)$. Deairing time was also significantly longer in the control group (12 minutes [interquartile range, 9-18] versus 9 minutes [interquartile range, 7-14 minutes]; $P=.002)$.
\end{abstract}

Conclusions: Carbon dioxide pericardial insufflation in open-chamber cardiac surgery does not affect postoperative neurocognitive decline. The most important factor is atheromatous vascular disease. (J Thorac Cardiovasc Surg 2012;144:646-53)

$\mathcal{B}$ Supplemental material is available online.

The use of carbon dioxide insufflation into the pericardial well is standard practice in cardiac surgery in many centers around the world. The rationale behind this practice is the

\footnotetext{
From the Department of Cardiothoracic Surgery, ${ }^{\text {a }}$ The Alfred Hospital, Melbourne, Australia; the Department of Surgery, ${ }^{b}$ Monash University, The Alfred Hospital, Melbourne, Australia; The Epworth Hospital, ${ }^{\mathrm{c}}$ Richmond, Victoria, Australia; the Department of Medicine (Neuroscience), ${ }^{\mathrm{d}}$ Monash University (Alfred Hospital campus), Melbourne, Australia; the Department of Epidemiology \& Preventive Medicine, ${ }^{\mathrm{e}}$ Monash University, Melbourne, Australia; and the Department of Anaesthesia, ${ }^{f}$ The Alfred Hospital, Melbourne, Australia.

Supported by the Australian Society of Cardiothoracic Surgeons.

Disclosures: Authors have nothing to disclose with regard to commercial support.

Received for publication Nov 21, 2011; revisions received March 9, 2012; accepted for publication April 3, 2012; available ahead of print May 14, 2012.

Address for reprints: Silvana F. Marasco, MSc, MBBS, FRACS, Acting Director of Department of Cardiothoracic Surgery, CJ Officer Brown, 3rd Floor, Alfred Hospital, Commercial Rd, Prahran, Melbourne 3181, Victoria, Australia (E-mail: s. marasco@alfred.org.au).

0022-5223/\$36.00

Crown Copyright (C) 2012 Published by Elsevier Inc. on behalf of The American Association for Thoracic Surgery

doi:10.1016/j.jtcvs.2012.04.010
}

increased density and solubility of carbon dioxide relative to air, potentially leading to fewer gaseous microemboli entering the bloodstream. Previous studies have argued that gaseous microemboli are a cause of type II neurocognitive decline after cardiac surgery. ${ }^{1,2}$ Despite the widespread use of carbon dioxide in cardiac surgery, however, it has recently been acknowledged that no study has conclusively proved its benefit in decreasing postoperative neurocognitive impairment. ${ }^{3-5}$

The main aim of this study was to analyze critically the neurocognitive outcomes of patients after open-chamber cardiac surgery to determine whether carbon dioxide pericardial insufflation reduces the incidence of neurocognitive decline (primary end point) as measured at 6 postoperative weeks. The secondary end point was to assess the utility of carbon dioxide insufflation in deairing of cardiac chambers as assessed by transesophageal echocardiography (TEE).

\section{MATERIALS AND METHODS}

A multicenter, prospective, double-blind, randomized, controlled trial was conducted to compare neurocognitive outcomes in patients undergoing open-chamber (left-sided) cardiac surgery who were assigned carbon 


\section{Abbreviations and Acronyms \\ DASS $=$ Depression Anxiety Stress Scale \\ TEE $=$ transesophageal echocardiography}

dioxide insufflation (carbon dioxide group) or medical air placebo (control group) in addition to undergoing standardized mechanical deairing maneuvers.

Inclusion criteria were as follows: listing for mitral or aortic valve operation, age older than 18 years and younger than 90 years, and adequate English language. Exclusion criteria were as follows: emergency operation, previous cerebrovascular event, active psychiatric conditions, preexisting cognitive impairment (Montreal Cognitive Assessment score less than 26 at preoperative screening). After written, informed consent was obtained, the recruited patients were randomly allocated on the morning of surgery. The randomization code was computer generated (Edgar II) with a 4-block randomization technique with unequal replication of treatments.

\section{Carbon Dioxide Delivery Method}

The CarbonAid device (Cardia Innovation AB, Stockholm, Sweden) is a gas diffuser reported to achieve the highest concentrations of carbon dioxide in the pericardial field. ${ }^{6}$ A pilot study of 7 patients was undertaken to analyze the levels of carbon dioxide achieved in the pericardial field. The CarbonAid gas diffuser achieved carbon dioxide concentrations greater than $98.56 \%$ at $5-\mathrm{L} / \mathrm{min}$ flow, and this was used for the carbon dioxide group. The control group had $0.5-\mathrm{L} / \mathrm{min}$ flow of medical air insufflated into the pericardial well, again with a CarbonAid device. All staff except the perfusionists were blinded to the gas being delivered to the patient. The diffuser was placed in the pericardial cavity $5 \mathrm{~cm}$ deep to the wound at the caudal end of the sternotomy, over the diaphragm, and carbon dioxide or medical air was delivered from just before opening of a left-sided chamber until closure of all left-sided chambers. The venous line was deaired before commencement of cardiopulmonary bypass. During the operation, all suction was kept out of the pericardial field when not in use to avoid transient reductions in carbon dioxide concentrations in the field, as previously recommended. ${ }^{5}$ When applied, the cardiotomy suction was limited to a maximum rate of $10 \mathrm{~L} / \mathrm{min}$ to avoid affecting the carbon dioxide concentrations in the field.

Standardized deairing maneuvers were used by all surgeons and included an aortic root vent and right superior pulmonary vein vent into the left ventricle. Mechanical deairing maneuvers used included steep Trendelenburg positioning during deairing and manipulation of the heart by hand to dislodge pockets of air. The aortic root was left in situ until the patient was weaned from cardiopulmonary bypass and was removed just before commencement of protamine. This was done before crossclamp removal until adequate deairing had been achieved, as determined by TEE examination of the cardiac chambers. This technique was standard across all surgeons in the study.

\section{Operative Procedure}

Cardiopulmonary bypass was conducted with a roller pump and hollowfiber membrane oxygenator maintaining nonpulsatile perfusion at 2 to 2.4 $\mathrm{L} /\left(\min \cdot \mathrm{m}^{2}\right)$, an arterial line filter was used, mean arterial pressure maintenance at 70 and $90 \mathrm{~mm} \mathrm{Hg}$, and cooling to $32^{\circ} \mathrm{C}$ to $34^{\circ} \mathrm{C}$. All cardiotomy and vent return was filtered through an integrated depth filter. The venous return was filtered by an integrated $47-\mu \mathrm{m}$ screen filter. Vacuum assisted venous drainage was not used. Gas sweep flows were adjusted to maintain $\mathrm{PaCO}_{2}$ at 35 to $40 \mathrm{~mm} \mathrm{Hg}$ with the alpha stat method. Perfusionist interventions into the venous circuit were monitored.
All patients were anesthetized with a balanced total intravenous technique consisting of propofol by continuous infusion, midazolam $(0.05-0.1 \mathrm{mg} / \mathrm{kg})$, and fentanyl $(15-2 \mu \mathrm{g} / \mathrm{kg})$, and muscle relaxation was maintained with long-acting nondepolarizing neuromuscular blockade. Bispectral index depth of anesthesia monitoring (Covidien plc, Dublin, Ireland) was routinely used, and anesthesia was adjusted to maintain a bispectral index of 40 to 60 . Intraoperative hemodynamic monitoring consisted of invasive arterial pressure monitoring, pulmonary artery catheter, and realtime TEE in every case.

TEE was used for continuous recording of intracardiac gas in the chambers at the time of removal of the aortic crossclamp until declaration of adequate deairing and on weaning from cardiopulmonary bypass. The time taken to achieve adequate deairing, as declared by the anesthetist, was also recorded. Midesophageal aortic valve long-axis views displaying the left ventricle, left ventricular outflow tract, and proximal ascending aorta were used to assess intracardiac air at the time of removal of the aortic crossclamp and on weaning from cardiopulmonary bypass. Further echocardiographic loops were captured once the anesthetist declared adequate deairing to have occurred. The recorded loops were graded by blinded assessors for each of the left atrium, left ventricle, and aorta according to the scale adapted from Kalpokas and colleagues ${ }^{7}$ (grade 0, no bubbles; grade 1, few bubbles; grade 2, moderate bubbles; grade 3, large bubbles).

Aortic atheromatous disease was also graded according to the following scale: grade 1, normal; grade 2, intimal thickening greater than $2 \mathrm{~mm}$ with or without calcification; grade 3 , atheroma less than $4 \mathrm{~mm}$ with or without calcification; grade 4 , atheroma at least $4 \mathrm{~mm}$ with or without calcification; and grade 5 , any mobile or ulcerated lesion with or without calcification. ${ }^{8}$ Grading was performed with TEE by the anesthetist assessing the first part of the ascending, transverse, and descending thoracic aorta, a method previously outlined as reliable. ${ }^{9}$

\section{Neurocognitive Testing}

The primary outcome measure of neurocognitive decline was assessed by a battery of tests performed preoperatively (between 1 and 4 weeks before surgery) and at 6 postoperative weeks. A combination of computerized testing and conventional tests was used, administered by trained assessors under the supervision of neuropsychologists and a neurologist. Sex, education level, and handedness were noted for each subject. Mood was also tested on the Depression Anxiety Stress Scale (DASS).

Six conventional neuropsychometric tests (Grooved Pegboard, Stroop test-Victoria version, Digit Span Forward and Digit Span Backward, 3 Letter Verbal Fluency Test [COWAT-F, A, S test], Five Point Design Fluency) and 5 tests (International Shopping List Delayed Recall, Detection Task, Identification Task, 1 Back-Working Memory Task, 1 Card Learning Task) on a computerized battery (CogState Ltd, Melbourne, Australia) were used. The 4 domains examined were psychomotor, episodic memory, attention and working memory, and executive function. All testing was performed in a quiet room. Neurocognitive test results were converted to $z$ scores according to published normative data with adjustments for age, sex, and education as appropriate. A change in $z$ score between preoperative and postoperative test performance of $1 \mathrm{SD}$ was considered to be clinically significant.

The trial was registered with the Australian and New Zealand Clinical Trials Registry on September 30, 2009, under the registration number ACTRN12609000844246. The study was conducted after approval had been gained from both the Alfred Hospital human rights and ethics committee (HREC) (approval number, 361/09) and the Epworth Hospital human rights and ethics committee (approval number, 48710).

\section{Statistical Analysis}

Data were analyzed with the SAS statistical software package (version 9.2; SAS Institute Inc, Cary, NC). Group comparisons were conducted with $\chi^{2}$ tests for equal proportions, paired Student $t$ tests for normally distributed data, and Wilcoxon rank sum tests otherwise. Results were reported as the 


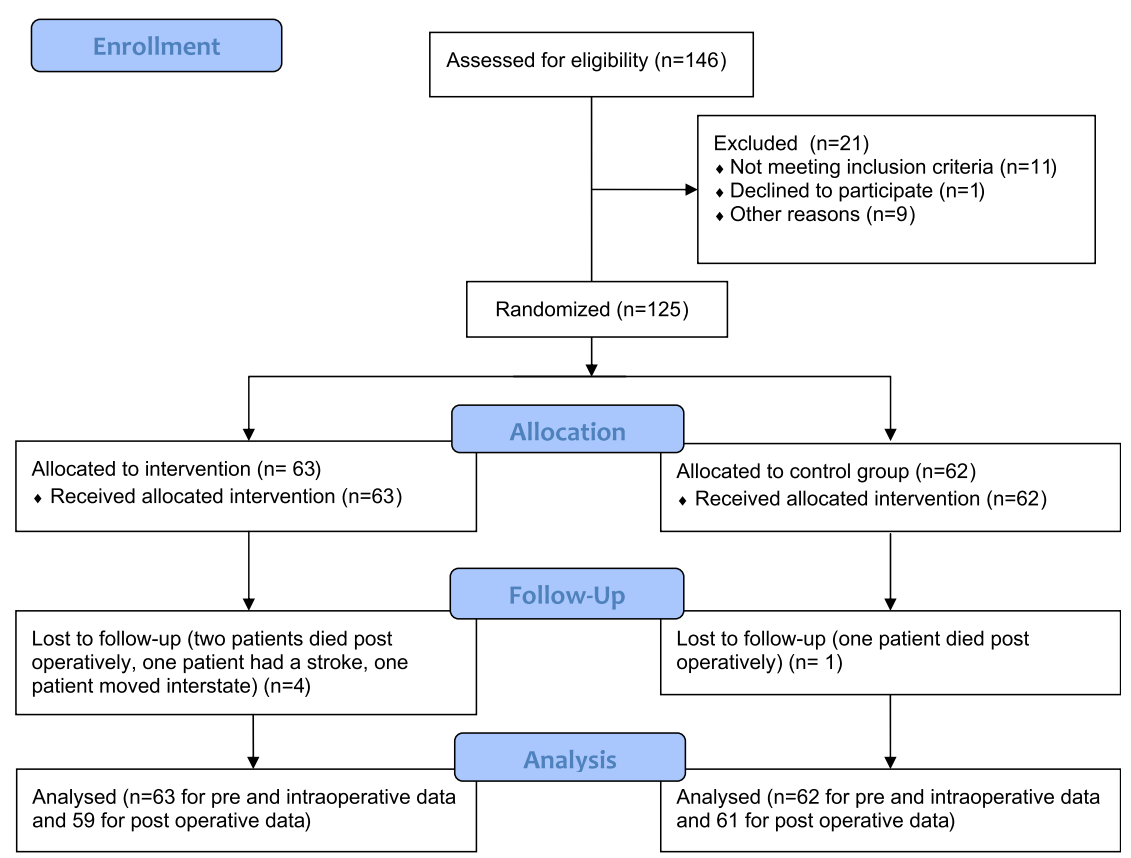

FIGURE 1. Study flow diagram, compliant with Consolidated Standards of Reporting Trials 2010.

number of patients with percentage, mean $\pm \mathrm{SD}$, or median with interquartile range as indicated. Neurocognitive test data were converted to $z$ scores and adjusted for age, sex, and education. Unweighted averages of the $z$ scores were determined for each domain (chosen a priori). Changes in neurocognitive function during the first 6 weeks were found to be well approximated by a normal distribution, so linear regression was used to determine the relationship with other variables. With 62 subjects per group, this study has an $80 \%$ power to detect a difference in continuously normally distributed outcomes equivalent to half of $1 \mathrm{SD}$ with a 2 -sided $P$ value of .05 . This difference of $0.5 \mathrm{SD}$ was to detect differences in the group data and not differences within the individual subjects, for which $1 \mathrm{SD}$ was considered significant.

\section{RESULTS \\ Recruitment}

One hundred forty-six patients were interviewed for enrollment between February 2010 and January 2011. Eleven patients were found to have a degree of preexisting cognitive impairment, as indicated by a Montreal Cognitive Assessment score lower than 26, and were therefore excluded. Of the 135 patients recruited, 1 withdrew consent, 3 subsequently refused surgery, 3 died while waiting for surgery, and 3 underwent surgery at another hospital. A total of 125 patients were therefore randomly allocated and underwent surgery (Figure 1).

There were no significant differences between groups in baseline demographic data except for baseline DASS depression score. Although the difference between groups was significant, it was not considered to be a clinically relevant difference because it represented an effect size less than 0.15 (Table 1).

There were no significant differences between groups in any of the operative variables (Table 2). There was significantly more intracardiac gas noted on intraoperative TEE in all cardiac chambers (left atrium, left ventricle, and aorta) and at all measured time points (after crossclamp removal, during weaning from cardiopulmonary bypass, and at declaration of adequate deairing by the anesthetist) in the control group than in the carbon dioxide group $(P<.04)$. Deairing time was also significantly longer in the control group (12 minutes [interquartile range, 9-18 minutes] versus 9 minutes [interquartile range, 7-14 minutes]; $P=.002$; Table E1). There were no significant differences in rates of cardiac complications or postoperative DASS scores (Table E2). In addition, no statistical differences were observed in DASS scores from baseline to postoperative testing in either group (not shown).

Neurocognitive testing showed no clinically significant differences in $z$ scores between preoperative and postoperative testing (defined as a change of $>1 \mathrm{SD}$; Table 3). Unweighted averages of the $z$ score results for the various tests were used to determine neurocognitive domain scores (Table 3). Unfortunately, normalized $z$ scores were not available for the International Shopping List tests, and a pooled result for episodic memory thus could not be calculated. The remaining 3 domains showed no differences between groups in their pooled results.

Linear regression was used to identify factors associated with decline in neurocognitive function. Table 4 shows negative parameter estimates, indicating that as the particular factor increases, it has a negative effect on neurocognitive outcome. The $R^{2}$ statistic provides estimates of the percentages of variation in outcome that can be explained by each 
TABLE 1. Baseline demographic data

\begin{tabular}{|c|c|c|c|}
\hline Characteristic & Control $(n=62)$ & Carbon dioxide $(n=63)$ & $P$ value \\
\hline Male/female ratio (no.) & $41 / 21(66 \%: 34 \%)$ & $31 / 32(49 \% / 51 \%)$ & .06 \\
\hline Age $(y$, mean $\pm S D)$ & $68.8 \pm 11.1$ & $67.5 \pm 12.3$ & .55 \\
\hline Education (no.) & & & .21 \\
\hline Left before finishing high school & $46(74 \%)$ & $42(67 \%)$ & \\
\hline Completed high school & $9(15 \%)$ & $12(19 \%)$ & \\
\hline Tertiary diploma/degree & $7(11 \%)$ & $9(14 \%)$ & \\
\hline Montreal Cognitive Assessment (mean \pm SD)) & $27.9 \pm 1.29$ & $28.13 \pm 1.43$ & .36 \\
\hline \multicolumn{4}{|c|}{ DASS baseline ( $z$ scores, median and interquartile range) } \\
\hline DASS Depression & $-0.14(-0.58$ to 0.81$)$ & $-0.28(-0.86$ to 0.14$)$ & .022 \\
\hline DASS Anxiety & $0.07(-0.52$ to 0.89$)$ & $0.07(-0.35$ to 0.65$)$ & .69 \\
\hline DASS Stress & $-0.52(-0.76$ to 0.35$)$ & $-0.39(-1$ to 0.04$)$ & .5 \\
\hline Preoperative sedatives or analgesia (no.) & $9(15 \%)$ & $9(15 \%)$ & .72 \\
\hline Hypertension (no.) & $46(74 \%)$ & $48(76 \%)$ & .84 \\
\hline Hypercholesterolemia (no.) & $41(66 \%)$ & $36(57 \%)$ & .36 \\
\hline Diabetes mellitus (no.) & $13(21 \%)$ & $8(13 \%)$ & .22 \\
\hline Respiratory disease (no.) & $11(18 \%)$ & $8(13 \%)$ & .45 \\
\hline Congestive heart failure (current, no.) & $8(13 \%)$ & $3(5 \%)$ & .11 \\
\hline Atrial fibrillation (no.) & $17(27 \%)$ & $12(19 \%)$ & .27 \\
\hline Thyroid disorder (no.) & $3(5 \%)$ & $1(2 \%)$ & .36 \\
\hline Peripheral vascular disease (no.) & $2(3 \%)$ & $3(5 \%)$ & .70 \\
\hline Preoperative creatinine $(\mu \mathrm{mol} / \mathrm{L}$, mean $\pm \mathrm{SD})$ & $112.23 \pm 38.06$ & $94.49 \pm 18.96$ & .36 \\
\hline Infective endocarditis (no.) & $3(5 \%)$ & 0 & .24 \\
\hline \multicolumn{3}{|c|}{ Breathless symptoms (New York Heart Association functional class, no.) } & .37 \\
\hline Class I & $8(13 \%)$ & $11(17 \%)$ & \\
\hline Class II & $33(53 \%)$ & $35(56 \%)$ & \\
\hline Class III & $20(32 \%)$ & $15(24 \%)$ & \\
\hline Class IV & $1(2 \%)$ & $2(3 \%)$ & \\
\hline \multicolumn{3}{|c|}{ Angina symptoms (Canadian Cardiovascular Society class, no.) } & .97 \\
\hline Class 0 & $49(79 \%)$ & $50(80 \%)$ & \\
\hline Class I & $2(3 \%)$ & $2(3 \%)$ & \\
\hline Class II & $9(15 \%)$ & $8(13 \%)$ & \\
\hline Class III & $2(3 \%)$ & $3(5 \%)$ & \\
\hline \multicolumn{4}{|l|}{ Cardiac pathology (no.) } \\
\hline Previous sternotomy & $8(13 \%)$ & $5(8 \%)$ & .36 \\
\hline Aortic valve disease & $48(77 \%)$ & $51(81 \%)$ & .24 \\
\hline Aortic stenosis & $35(59 \%)$ & $39(63 \%)$ & 69 \\
\hline Aortic regurgitation & $13(22 \%)$ & $16(25 \%)$ & .63 \\
\hline Mitral valve disease & $19(31 \%)$ & $15(24 \%)$ & .29 \\
\hline Mitral stenosis & $1(2 \%)$ & 0 & .50 \\
\hline Mitral regurgitation & $18(30 \%)$ & $15(24 \%)$ & .47 \\
\hline Coronary artery disease & $22(35 \%)$ & $22(35 \%)$ & .95 \\
\hline
\end{tabular}

DASS, Depression Anxiety Stress Scale; $S D$, Standard deviation.

predictor variable. All data collected on the patients was entered into this analysis to ensure that every potential factor was assessed. Graded assessment of gas in the left-sided chambers showed no correlation with neurocognitive outcomes. The factors most strongly associated with neurocognitive decline were hypercholesterolemia, aortic atheroma grade, and coronary artery disease.

\section{DISCUSSION}

We found no difference in neurocognitive outcomes at 6 weeks with the use of carbon dioxide versus standard mechanical deairing maneuvers alone during open-chamber cardiac surgery. Carbon dioxide use did lead to fewer gaseous emboli in the cardiac chambers during weaning from cardiopulmonary bypass, and it shortened deairing times by at least 3 minutes. This did not translate into improved neurocognitive outcomes at 6 weeks, however, suggesting that sufficient deairing can be achieved through mechanical deairing maneuvers alone.

This study was performed in patients undergoing surgery through a midline sternotomy only. In minimally invasive open-chamber cardiac surgery, the ability to perform mechanical deairing maneuvers is more limited, and in these circumstances carbon dioxide may have a more important 
TABLE 2. Operative variables

\begin{tabular}{|c|c|c|c|}
\hline Characteristic & $\begin{array}{l}\text { Control } \\
(\mathrm{n}=62)\end{array}$ & $\begin{array}{l}\text { Carbon dioxide } \\
\quad(n=63)\end{array}$ & $\begin{array}{c}P \\
\text { value }\end{array}$ \\
\hline Operations (no.) & & & .676 \\
\hline Aortic valve replacement & 43 & 47 & \\
\hline Mitral valve replacement & 7 & 3 & \\
\hline Mitral valve repair & 8 & 10 & \\
\hline Aortic root & 2 & 2 & \\
\hline Ascending aorta & 2 & 1 & \\
\hline Valve type (no.) & & & .370 \\
\hline Bioprosthetic valve & 39 & 40 & \\
\hline Mechanical valve & 12 & 10 & \\
\hline $\begin{array}{l}\text { Concomitant coronary artery } \\
\text { bypass grafting (no.) }\end{array}$ & $22(35 \%)$ & $22(35 \%)$ & .95 \\
\hline $\begin{array}{l}\text { No. of coronary grafts } \\
\quad(\text { mean } \pm \mathrm{SD})\end{array}$ & $1.76 \pm 0.83$ & $1.73 \pm 0.93$ & .90 \\
\hline Aortic atheroma grade & & & .28 \\
\hline Grade 1 & 33 & 29 & \\
\hline Grade 2 & 18 & 16 & \\
\hline Grade 3 & 7 & 13 & \\
\hline Grade 4 & 1 & 4 & \\
\hline Missing data & 3 & 1 & \\
\hline CPB time (min, mean $\pm \mathrm{SD}$ ) & $118.3 \pm 48.5$ & $113.4 \pm 47.2$ & .56 \\
\hline $\begin{array}{l}\text { Crossclamp time (min, } \\
\text { mean } \pm \mathrm{SD})\end{array}$ & $91.8 \pm 42.4$ & $88.9 \pm 38.1$ & .68 \\
\hline $\begin{array}{l}\text { Reperfusion time* (min, } \\
\text { mean } \pm \text { SD) }\end{array}$ & $16.35 \pm 9.15$ & $18.4 \pm 15.6$ & .38 \\
\hline $\begin{array}{l}\text { Lowest temperature } \\
\qquad\left({ }^{\circ} \mathrm{C}, \text { mean } \pm \mathrm{SD}\right)\end{array}$ & $33.3 \pm 2.23$ & $33.5 \pm 1.0$ & .54 \\
\hline $\begin{array}{l}\text { Lowest potassium }(\mathrm{mEq} / \mathrm{L} \\
\text { mean } \pm \mathrm{SD})\end{array}$ & $4.72 \pm 0.66$ & $4.67 \pm 0.59$ & .68 \\
\hline Cannulation (no.) & & & .214 \\
\hline Unicaval & $44(71 \%)$ & $51(81 \%)$ & \\
\hline Bicaval & $18(30 \%)$ & $12(19 \%)$ & \\
\hline \multicolumn{4}{|l|}{ Chambers opened (no.) } \\
\hline Aorta opened & $49(79 \%)$ & $53(84 \%)$ & .42 \\
\hline Left atrium opened & $15(24 \%)$ & $16(25 \%)$ & .85 \\
\hline Both pleura opened & $3(5 \%)$ & $3(5 \%)$ & $>.999$ \\
\hline \multicolumn{4}{|l|}{ Venting (no.) } \\
\hline $\begin{array}{l}\text { Right superior pulmonary } \\
\text { vein vent }\end{array}$ & $58(94 \%)$ & $58(92 \%)$ & .41 \\
\hline Aortic root vent & $60(97 \%)$ & $59(94 \%)$ & .24 \\
\hline Vent problems & 0 & $3(5 \%)$ & .73 \\
\hline Gas after deairing & $4(6 \%)$ & $5(8 \%)$ & $>.999$ \\
\hline Gas in venous line & $4(6 \%)$ & $4(6 \%)$ & $>.999$ \\
\hline $\begin{array}{l}\text { No. of blood samples during } \\
\quad \text { CBP }(\text { mean } \pm \text { SD) }\end{array}$ & $4.4 \pm 2.6$ & $4.2 \pm 2.4$ & .73 \\
\hline $\begin{array}{l}\text { No. of medication injections } \\
\quad(\text { median and IQR) }\end{array}$ & $5(3-10)$ & $7(4-10)$ & .16 \\
\hline $\begin{array}{l}\text { Total perfusion interventions } \\
\text { (median and IQR) }\end{array}$ & $9(7-15)$ & $11(8-17)$ & .29 \\
\hline
\end{tabular}

(Continued)

role to play. Previous studies looking at pericardial carbon dioxide insufflation have mostly concentrated on detection of intracardiac air. ${ }^{3}$ Two studies have included
TABLE 2. Continued

\begin{tabular}{|c|c|c|c|}
\hline Characteristic & $\begin{array}{l}\text { Control } \\
(\mathrm{n}=62)\end{array}$ & $\begin{array}{l}\text { Carbon dioxide } \\
\quad(\mathbf{n}=63)\end{array}$ & $\begin{array}{c}P \\
\text { value }\end{array}$ \\
\hline $\begin{array}{l}\text { Perioperative complications } \\
\text { (no.) }\end{array}$ & & & \\
\hline Ventricular fibrillation & $4(7 \%)$ & $11(17 \%)$ & .06 \\
\hline $\begin{array}{l}\text { ST segment changes on } \\
\text { electrocardiograph during } \\
\text { weaning from CPB (no.) }\end{array}$ & $6(10 \%)$ & $1(2 \%)$ & .06 \\
\hline
\end{tabular}

neurocognitive testing, and neither showed a difference in neurocognitive outcome $e^{4,10}$; however, the test battery in those 2 studies was very small, and the testing was conducted very early postoperatively (5 days), when the results could have been confounded by the effects of analgesia and anesthesia.

In 1995, a Statement of Consensus recommended a battery of tests for neurocognitive testing in cardiac patients. ${ }^{11}$ This statement is now outdated, however, and we chose to use a larger battery of tests combining both conventional and computerized testing to ensure that 4 neurocognitive domains (chosen a priori) were adequately tested. On the basis of efficiency of administration, reduction of practice effects, and high correlation with conventional testing, CogState, a computerized test battery that has been well validated in the literature, was chosen. ${ }^{12,13}$

Once gaseous microemboli reach the brain, the proposed mechanisms of cerebral injury are occlusion of small vessels causing distal ischemia and activation of the inflammatory cascade to exacerbate such injury and reactive hyperemia. ${ }^{1}$ There is difficulty in proving that gaseous microemboli cause organic brain lesions, however, because of the inability to distinguish reliably between solid and gaseous emboli with various detection modalities. A recent systematic review concluded that there is insufficient evidence at this time to prove a causal link between intraoperative cerebral microemboli and postoperative cognitive function. ${ }^{14}$ That study focused on high-intensity transient signals in patients undergoing cardiac, carotid, and orthopedic surgery and did not discriminate between gaseous and particulate microemboli. In light of the failure to find a causal link when including all types of microemboli, it may be even more difficult to prove a link when investigating gaseous emboli alone.

There are other benefits of carbon dioxide use reported in the literature, such as prevention of coronary artery gas embolism. We recorded surrogate markers of coronary artery gas embolism, such as ventricular fibrillation after crossclamp removal and ST segment elevation during or after coming off bypass, but found no statistically significant differences between groups, although there was a trend 
TABLE 3. Neurocognitive $z$ scores

\begin{tabular}{|c|c|c|c|}
\hline Neurocognitive tests & Control $(n=62)$ & Carbon dioxide $(n=63)$ & $P$ value \\
\hline \multicolumn{4}{|l|}{ Psychomotor Domain } \\
\hline \multicolumn{4}{|l|}{ Grooved Pegboard } \\
\hline Preoperative & $-0.61(-3.06$ to -0.29$)$ & $-0.48(-2.12$ to -0.4$)$ & .68 \\
\hline Postoperative & $-1.5(-3.31$ to -0.13$)$ & $-1.08(-3.48$ to -0.23$)$ & .49 \\
\hline Difference & $-0.63(-1.26$ to -0.17$)$ & $-0.6(-1.52$ to -0.03$)$ & .69 \\
\hline \multicolumn{4}{|l|}{ Detection Task } \\
\hline Preoperative & $-0.33(-0.73$ to -0.07$)$ & $-0.13(-0.47$ to -0.07$)$ & .07 \\
\hline Postoperative & $-0.16(-0.53$ to -0.13$)$ & $-0.13(-0.8$ to -0.2$)$ & .63 \\
\hline Difference & $0.17(-0.06$ to 0.20$)$ & $0(-0.33$ to 0.17$)$ & .028 \\
\hline \multicolumn{4}{|c|}{ Episodic Memory Domain } \\
\hline \multicolumn{4}{|c|}{ One Card Learning Task } \\
\hline Preoperative & $-0.27(-0.47$ to -0.16$)$ & $-0.07(-0.33$ to -0.2$)$ & .12 \\
\hline Postoperative & $-0.13(-0.47$ to -0.13$)$ & $-0.07(-0.33$ to -0.13$)$ & .59 \\
\hline Difference & $0.14(0.00-0.03)$ & $0.00(0.00$ to -0.07 & 671 \\
\hline \multicolumn{4}{|c|}{ Delayed Recall Shopping List } \\
\hline Preoperative & $7.7 \pm 2.08$ & $7.82 \pm 2.55$ & .79 \\
\hline Postoperative & $7.84 \pm 2.56$ & $8.09 \pm 2.24$ & .57 \\
\hline Difference & $0.13 \pm 1.62$ & $0.26 \pm 2.45$ & .74 \\
\hline \multicolumn{4}{|c|}{ Attention/Working Memory Domain } \\
\hline \multicolumn{4}{|l|}{ Digit Span Forward } \\
\hline Preoperative & $-2(-2$ to 0$)$ & $-1(-2$ to 0$)$ & .52 \\
\hline Postoperative & $-2(-3$ to -1$)$ & $-2(-3$ to 0$)$ & .87 \\
\hline Difference & $0(0-0)$ & $0(0-0)$ & .47 \\
\hline \multicolumn{4}{|l|}{ Digit Span Backward } \\
\hline Preoperative & $-2(-3$ to -1$)$ & $-2(-3$ to -1$)$ & .84 \\
\hline Postoperative & $-2(-3$ to -1$)$ & $-2(-3$ to -1$)$ & .97 \\
\hline Difference & $0(0-0)$ & $0(-0.5$ to 1$)$ & .39 \\
\hline \multicolumn{4}{|l|}{ One Back Task } \\
\hline Preoperative & $-0.1(-0.63$ to -0.23$)$ & $-0.2(-0.6$ to -0.27$)$ & .84 \\
\hline Postoperative & $0.13(-0.23$ to -0.4$)$ & $0.2(-0.33$ to -0.53$)$ & .8 \\
\hline Difference & $0.23(0.0$ to -0.53$)$ & $0.20(0.07$ to -0.60$)$ & .92 \\
\hline \multicolumn{4}{|l|}{ Identification Task } \\
\hline Preoperative & $-0.13(-0.4$ to -0.1$)$ & $-0.07(-0.4$ to -0.07$)$ & .88 \\
\hline Postoperative & $-0.07(-0.27$ to 0.27$)$ & $-0.07(-0.33$ to 0.20$)$ & .78 \\
\hline Difference & $0.20(-0.07$ to 0.47$)$ & 0.07 (0.0 to 0.47$)$ & .57 \\
\hline \multicolumn{4}{|c|}{ Executive Function Domain } \\
\hline \multicolumn{4}{|l|}{ Stroop Test } \\
\hline Preoperative & $-0.108 \pm 0.63$ & $0.036 \pm 0.71$ & .23 \\
\hline Postoperative & $0.103 \pm 0.66$ & $0.034 \pm 0.69$ & .58 \\
\hline Difference & $0.2 \pm 0.46$ & $-0.03 \pm 0.47$ & .01 \\
\hline \multicolumn{4}{|c|}{3 Letter Verbal Fluency } \\
\hline Preoperative & $0.0034 \pm 1.29$ & $0.33 \pm 1.24$ & .15 \\
\hline Postoperative & $0.227 \pm 1.24$ & $0.46 \pm 1.32$ & .32 \\
\hline Difference & $0.28(0$ to -0.61$)$ & $0.24(-0.08$ to -0.56$)$ & .55 \\
\hline \multicolumn{4}{|l|}{ Five Point Test } \\
\hline Preoperative & $-0.42(-1.31$ to -0.71$)$ & $-0.12(-0.95$ to -0.71$)$ & .39 \\
\hline Postoperative & $-0.36(-1.31$ to -0.71$)$ & $0(-0.71$ to -1.07$)$ & .17 \\
\hline Difference & $0(-0.23$ to -0.48$)$ & $0.18(-0.12$ to -0.47$)$ & .36 \\
\hline \multicolumn{4}{|c|}{ Neurocognitive domain scores } \\
\hline \multicolumn{4}{|l|}{ Psychomotor } \\
\hline Preoperative & $-0.59(-1.67$ to 0.04$)$ & $-0.46(-1.97$ to 0.18$)$ & .57 \\
\hline Postoperative & $-0.78(-2.31$ to -0.11$)$ & $-0.51(-1.94$ to 0.02$)$ & .41 \\
\hline Difference & $-0.2(-0.6$ to 0.18$)$ & $-0.17(-0.76$ to 0.24$)$ & .86 \\
\hline
\end{tabular}


TABLE 3. Continued

\begin{tabular}{|c|c|c|c|}
\hline Neurocognitive tests & Control $(n=62)$ & Carbon dioxide $(n=63)$ & $P$ value \\
\hline \multicolumn{4}{|c|}{ Attention/Working Memory } \\
\hline Preoperative & $-0.63(-1.15$ to -0.35$)$ & $-0.72(-1.41$ to -0.15$)$ & .9 \\
\hline Postoperative & $-0.71 \pm 0.74$ & $-0.57 \pm 0.76$ & .31 \\
\hline Difference & $0.05 \pm 0.37$ & $0.08 \pm 0.51$ & .72 \\
\hline \multicolumn{4}{|l|}{ Executive function } \\
\hline Preoperative & $-0.1 \pm 0.86$ & $0.14 \pm 0.88$ & .13 \\
\hline Postoperative & $0.05 \pm 0.78$ & $0.26 \pm 0.96$ & .2 \\
\hline Difference & $0.14(-0.01$ to 0.42$)$ & $0.18(-0.08$ to 0.39$)$ & .69 \\
\hline
\end{tabular}

Results reported as median with interquartile range or mean \pm SD.

toward less ST segment elevation in the carbon dioxide group. In this trial, we did not observe any of the previously reported complications of carbon dioxide use such as hemodynamic compromise, hypercarbia, ${ }^{15}$ or hyperkalemia caused by increased carbon dioxide leading to leaching of potassium ions. ${ }^{16}$

We used linear regression analysis to identify factors associated with neurocognitive decline in our patient cohort. Unlike previous studies, we found no association between the total number of perfusionist interventions and neurocognitive decline ${ }^{1,2}$; however, we did find age, hypercholesterolemia, aortic atheroma grade, and coronary artery disease to be strong predictors of neurocognitive impairment in this study. It could be argued that all these factors are essentially markers for a single

TABLE 4. Factors associated with decline in neurocognitive function

\begin{tabular}{lcccc}
\hline \multicolumn{1}{c}{ Variable } & Estimate & SE & $\boldsymbol{P}$ value & $\boldsymbol{R}^{\mathbf{2}}$ \\
\hline Variables associated with decline in & executive & function & domain & \\
Hypercholesterolemia & -0.33 & 0.09 & .001 & 9.69 \\
Coronary artery disease & -0.27 & 0.10 & .006 & 6.14 \\
Age & -0.01 & 0.00 & .020 & 4.47 \\
Hypertension & -0.24 & 0.11 & .03 & 3.93 \\
Grade gas in left atrium & 0.10 & 0.05 & .057 & 3.09 \\
Grade gas in left ventricle & 0.10 & 0.06 & .078 & 2.65 \\
Grade gas in aorta & 0.10 & 0.06 & .088 & 2.49 \\
Variables associated with decline in attention domain & & \\
Hypercholesterolemia & -0.229 & 0.081 & .0052 & 6.42 \\
Number coronary artery grafts & -0.100 & 0.040 & .0141 & 5.00 \\
Coronary artery disease & -0.097 & 0.042 & .0218 & 4.38 \\
Aortic atheroma grade & -0.104 & 0.046 & .0236 & 4.38 \\
Hypertension & -0.203 & 0.093 & .0316 & 3.86 \\
Age & -0.007 & 0.003 & .0513 & 3.18 \\
Postoperative atrial fibrillation & -0.155 & 0.087 & .0777 & 2.61 \\
Gas after deairing & 0.198 & 0.154 & .2020 & 1.39 \\
Variables associated with decline in psychomotor domain & & \\
Aortic atheroma grade & -0.37 & 0.11 & .0016 & 8.37 \\
Hypercholesterolemia & -0.60 & 0.21 & .0041 & 6.78 \\
Ventricular fibrillation after & -0.72 & 0.31 & .0218 & 4.42 \\
removal of crossclamp & \multicolumn{5}{c}{} & & \\
Grade gas in left ventricle & 0.21 & 0.12 & .0709 & 2.79 \\
Grade gas in aorta & 0.43 & 0.30 & .1596 & 1.73 \\
Grade gas in left atrium & 0.26 & 0.21 & .2347 & 1.24 \\
\hline
\end{tabular}

risk factor, atheromatous vascular disease. Increasing age has also been demonstrated to predict independently neurocognitive decline after cardiac surgery. ${ }^{17}$

Numerous studies have implicated atheromatous disease in type II neurocognitive dysfunction after cardiac surgery and have recommended techniques such as avoidance of crossclamping of the aorta. ${ }^{18}$ Furthermore, atherosclerosis of the heart is closely correlated with microvascular disease of the brain and thus with the potential for greater susceptibility to neurocognitive insult after cardiac surgery. ${ }^{19}$ All these findings point to the higher relative importance of solid microemboli compared with gaseous microemboli when considering neurocognitive impairment. Cardiopulmonary bypass itself has also been implicated in postoperative neurocognitive dysfunction, but a recent meta-analysis of on-pump versus off-pump coronary artery bypass grafting failed to find significant differences between groups. ${ }^{20}$

Selnes and colleagues ${ }^{21}$ compared medically treated patients with coronary artery disease with cardiac surgical patients for five years and found no significant differences in neurocognitive decline between groups ${ }^{21}$; however, neurocognitive decline was seen in both groups during the 5 -year period. This finding supports preexisting cerebrovascular disease as more influential than intraoperative factors in long-term neurocognitive decline in cardiac surgical patients. ${ }^{19,22}$

Subjective cognitive complaints from patients and relatives after cardiac surgery have identified memory as the most commonly affected neurocognitive domain. ${ }^{23}$ Perhaps that is because it is the cognitive area that is most identifiable to patients and their families. More objective assessments of patients after cardiac surgery have identified attention and information processing speed as the cognitive areas most likely to be affected. ${ }^{24,25}$

One possible limitation of this study is that we did not collect data on which patients underwent carotid artery screening. We screen patients for carotid disease if they have a history of cerebrovascular accident or transient ischemic attack. Such patients would have been excluded from enrolment in this trial. We also screen for patients who have left main stenosis. 
In conclusion, this study shows that carbon dioxide pericardial insufflation in open chamber cardiac surgery does not affect postoperative neurocognitive decline and that the most important factor is atheromatous vascular disease. The usefulness of carbon dioxide insufflation in minimally invasive and robotic surgery was not assessed in this trial, but given the inherent restrictions on deairing maneuvers in those types of operations, it is likely that carbon dioxide use will remain beneficial, although this has not been formally studied to our knowledge.

\section{References}

1. Borger MA, Peniston CM, Weisel RD, Vasiliou M, Green RE, Feindel CM. Neuropsychologic impairment after coronary bypass surgery: effect of gaseous microemboli during perfusionist interventions. J Thorac Cardiovasc Surg. 2001; 121:743-9.

2. Taylor RL, Borger MA, Weisel RD, Fedorko L, Feindel CM. Cerebral microemboli during cardiopulmonary bypass: increased emboli during perfusionist interventions. Ann Thorac Surg. 1999;68:89-93.

3. Chaudhuri K, Marasco SF. The effect of carbon dioxide insufflation on cognitive function during cardiac surgery. J Card Surg. 2011;26:189-96.

4. Martens S, Neumann K, Sodemann C, Deschka H, Wimmer-Greinecker G, Moritz A. Carbon dioxide field flooding reduces neurologic impairment after open heart surgery. Ann Thorac Surg. 2008;85:543-7.

5. Svenarud P, Persson M, van der Linden J. Effect of $\mathrm{CO}_{2}$ insufflation on the number and behavior of air microemboli in open-heart surgery: a randomized clinical trial. Circulation. 2004;109:1127-32.

6. Persson M, Svenarud P, van der Linden J. What is the optimal device for carbon dioxide deairing of the cardiothoracic wound and how should it be positioned? $J$ Cardiothorac Vasc Anesth. 2004;18:180-4.

7. Kalpokas MV, Nixon IK, Kluger R, Beilby DS, Silbert BS. Carbon dioxide field flooding versus mechanical de-airing during open-heart surgery: a prospective randomized controlled trial. Perfusion. 2003;18:291-4

8. Khatibzadeh M, Mitusch R, Stierle U, Gromoll B, Sheikhzadeh A. Aortic atherosclerotic plaques as a source of systemic embolism. J Am Coll Cardiol. 1996;27: 664-9.

9. Wilson MJ, Boyd SYN, Lisagor PG, Rubal BJ, Cohen DJ. Ascending aortic atheroma assessed intraoperatively by epiaortic and transesophageal echocardiography. Ann Thorac Surg. 2000;70:25-30.

10. Martens S, Dietrich M, Wals S, Steffen S, Wimmer-Greinecker G, Moritz A. Conventional carbon dioxide application does not reduce cerebral or myocardial damage in open heart surgery. Ann Thorac Surg. 2001;72:1940-4.
11. Murkin JM, Newman SP, Stump DA, Blumenthal JA. Statement of consensus on assessment of neurobehavioral outcomes after cardiac surgery. Ann Thorac Surg. 1995;59:1289-95.

12. Collie A, Maruff P, Makdissi M, McCrory P, McStephen M, Darby D. CogSport: reliability and correlation with conventional cognitive tests used in post concussion medical evaluations. Clin J Sport Med. 2003;13:28-32.

13. Maruff P, Thomas E, Cysique L, Brew B, Collie A, Snyder P, et al. Validity of the CogState brief battery: relationship to standardized tests and sensitivity to cognitive impairment in mild traumatic brain injury, schizophrenia, and AIDS dementia complex. Arch Clin Neuropsychol. 2009;24: 165-78.

14. Martin KK, Wigginton JB, Babikian VL, Pochay VE, Crittenden MD, Rudolph JL. Intraoperative cerebral high-intensity transient signals and postoperative cognitive function: a systematic review. Am J Surg. 2009;197:55-63.

15. Nadolny EM, Svensson LG. Carbon dioxide field flooding techniques for open heart surgery: monitoring and minimizing potential adverse effects. Perfusion. 2000;15:151-3.

16. Lippmann M. Complications of $\mathrm{CO}_{2}$ flooding the surgical field in open heart surgery: an old technique revisited. Anesth Analg. 1998;87:978-9.

17. Newman MF, Croughwell ND, Blumenthal JA, Lowry E, White WD, Spillane W, et al. Predictors of cognitive decline after cardiac operation. Ann Thorac Surg. 1995;59:1326-30.

18. Hammon JW, Stump DA, Butterworth JF, Moody DM, Rorie K, Deal DD, et al Single crossclamp improves 6-month cognitive outcome in high-risk coronary bypass patients: the effect of reduced aortic manipulation. J Thorac Cardiovasc Surg. 2006;131:114-21.

19. Selnes OA, Gottesman RF. Neuropsychological outcomes after coronary artery bypass grafting. J Int Neuropsychol Soc. 2010;16:221-6.

20. Marasco SF, Sharwood LN, Abramson MJ. No improvement in neurocognitive outcomes after off-pump versus on-pump coronary revascularisation: a metaanalysis. Eur J Cardiothorac Surg. 2008;33:961-70.

21. Selnes OA, Grega MA, Borowicz LM Jr, Barry S, Zeger S, Baumgartner WA et al. Cognitive outcomes three years after coronary artery bypass surgery: a comparison of on-pump coronary artery bypass graft surgery and nonsurgical controls. Ann Thorac Surg. 2005;79:1201-9.

22. Stroobant N, Vingerhoets G. Pre-existing cognitive impairment in candidates for cardiac surgery: an overview. Heart. 2009;95:1820-5.

23. Bergh C, Backström M, Jönsson H, Havinder L, Johnsson P. In the eye of both patient and spouse: memory is poor 1 to 2 years after coronary bypass and angioplasty. Ann Thorac Surg. 2002;74:689-94.

24. Andrew MJ, Baker RA, Bennetts J, Kneebone AC, Knight JL. A comparison of neuropsychologic deficits after extracardiac and intracardiac surgery. $J$ Cardiothorac Vasc Anesth. 2001;15:9-14.

25. Raymond PD, Hinton-Bayre AD, Radel M, Ray MJ, Marsh NA. Assessment of statistical change criteria used to define significant change in neuropsychological test performance following cardiac surgery. Eur J Cardiothorac Surg. 2006;29:82-8. 
TABLE E1. Transesophageal assessment of intracardiac air

\begin{tabular}{lccc}
\hline Characteristic & $\begin{array}{c}\text { Control } \\
(\mathbf{n}=\mathbf{6 2})\end{array}$ & $\begin{array}{c}\text { Carbon dioxide } \\
(\mathbf{n}=\mathbf{6 3})\end{array}$ & $\boldsymbol{P}$ value \\
\hline Maximal gas bubble grade* & & & \\
$\quad$ After crossclamp removal & & & \\
$\quad$ Left atrium & $1(1-2)$ & $1(1-1)$ & .009 \\
$\quad$ Left ventricle & $2(1-2)$ & $1(1-1)$ & .001 \\
$\quad$ Aorta & $1(0-2)$ & $1(0-1)$ & .038 \\
During weaning from cardiopulmonary bypass & \\
$\quad$ Left atrium & $1(1-2)$ & $1(1-2)$ & .019 \\
$\quad$ Left ventricle & $2(1-2)$ & $1(0-1)$ & $<.0001$ \\
$\quad$ Aorta & $1(1-2)$ & $1(0-1)$ & .0003 \\
After adequate deairing & $1(1-2)$ & $1(0-1)$ & .002 \\
$\quad$ Left atrium & $1(0-1)$ & $1(0-0)$ & $<.0001$ \\
$\quad$ Left ventricle & $1(0-1)$ & $1(0-0)$ & .0035 \\
$\quad$ Aorta & & & .002 \\
Duration of gas bubbles & $12(9-18)$ & $9(7-14)$ & \\
Total deairing time (mean) &
\end{tabular}

*Data are median with interquartile range except as marked.

TABLE E2. Postoperative data

\begin{tabular}{|c|c|c|c|}
\hline Characteristic & Control $(n=62)$ & Carbon dioxide $(n=63)$ & $P$ value \\
\hline Death & $1(1.61 \%)$ & $2(3.17 \%)$ & .319 \\
\hline Cerebrovascular accident (type I neurologic injury) & 0 & 1 & .568 \\
\hline Prolonged mechanical ventilation* & 12 & 5 & .112 \\
\hline Prolonged inotrope use ( $>4 \mathrm{~h})$ & 22 & 15 & .160 \\
\hline Low cardiac output syndrome & 14 & 5 & .024 \\
\hline Low systemic vascular resistance syndrome & 9 & 3 & .073 \\
\hline Perioperative acute myocardial infarction & 0 & 0 & 1.0 \\
\hline Perioperative cardiogenic shock & 1 & 1 & 1.0 \\
\hline Atrial fibrillation & $23(37 \%)$ & $18(29 \%)$ & .75 \\
\hline Deep sternal wound infection & 0 & 0 & 1.0 \\
\hline Postoperative sedatives or analgesia at $6 \mathrm{wk}$ & $9(15 \%)$ & $7(11 \%)$ & .69 \\
\hline \multicolumn{4}{|l|}{ DASS postoperative ( $z$ scores) } \\
\hline DASS Depression & $-0.14(-0.72$ to 0.75$)$ & $-0.42(-0.86$ to 0$)$ & .09 \\
\hline DASS Anxiety & $-0.15(-0.74$ to 0.5$)$ & $-0.15(-0.96$ to 0.26$)$ & .24 \\
\hline DASS Stress & $-0.52(-0.91$ to 0.09$)$ & $-0.65(-1$ to 0.15$)$ & .25 \\
\hline
\end{tabular}

Data are number of patients or median with interquartile range. DASS, Depression Anxiety Stress Scale. *Mechanical ventilation longer than 24 hours in duration. 